\title{
The metabolic effects of a high fructose versus a high glucose diet in healthy overweight men
}

\author{
R. D. Johnston ${ }^{1,2}$, M. C. Stephenson ${ }^{3}$, H. Crossland ${ }^{1}$, S. M. Cordon ${ }^{1}$, M. A. Taylor, \\ G. P. Aithal ${ }^{2}$ and I. A. Macdonald \\ ${ }^{1}$ School of Biomedical Sciences, University of Nottingham, ${ }^{2}$ Nottingham Digestive Diseases Centre: National Institute for \\ Health Research Biomedical research Unit, Nottingham University Hospitals and ${ }^{3}$ Sir Peter Mansfield Magnetic Resonance \\ Centre, University of Nottingham, NG7 2UH, UK
}

Fructose and glucose have differing metabolic response and catabolic pathways described ${ }^{(1)}$. Divergent clinical outcomes however in terms of lipidaemia, ectopic lipid storage and insulin resistance have rarely and inconsistently been reported ${ }^{(2,3)}$. There is no prior comparative data in healthy overweight men, none in the isoenergetic state and scant data on hepatic outcomes.

32 healthy, centrally overweight males were randomised to 2 periods each of 2 weeks of either a high fructose or glucose intake in a non-crossover fashion. Isoenergetic status was maintained by providing foodstuffs during the first period, followed by a 6 week washout and then a second period of ad libitum overfeeding. The sugars contributed $25 \%$ of predicted total energy requirements, and were consumed four times a day dissolved in water.

Hepatic triglyceride content $\left({ }^{1} \mathrm{H}\right.$ MRS) was the primary outcome measurement, with further assessments from ${ }^{1} \mathrm{H}$ MRS of soleus muscle, deuterated glucose hyperinsulinaemic euglycaemic clamps, indirect calorimetry and finometry.

The groups were well matched at study entry. Overall the subjects' mean age was 34 years, BMI $29.4 \mathrm{~kg} / \mathrm{m}^{2}$ and dose of sugars was $217 \mathrm{~g}$ daily. The changes in the primary measures are shown in the table below. There were no changes during the isoenergetic period and matched changes during overfeeding. Further to this the groups did not differ in terms of satiety, whole body oxidative profile, hepatic insulin resistance, non-oxidative glucose disposal, intramyocellular triglyceride, renal function or haemodynamic parameters. Nonesterified fatty acids were reduced during both periods with fructose and only in the overfeeding period by glucose. Uric acid concentrations rose with fructose and fell with glucose, particularly during the isoenergetic period.

\begin{tabular}{|c|c|c|c|c|c|c|}
\hline & \multirow[b]{2}{*}{ Period } & \multicolumn{2}{|c|}{ Fructose } & \multicolumn{2}{|c|}{ Glucose } & \multirow[b]{2}{*}{ Sig between groups } \\
\hline & & Mean & $\overline{\mathrm{SD}}$ & Mean & $\overline{\mathrm{SD}}$ & \\
\hline \multirow[t]{2}{*}{ Weight (kg) } & Isoenergetic & -0.26 & 0.92 & -0.12 & 0.70 & 0.62 \\
\hline & Overfeeding & $1.03 *$ & 1.37 & $0.57 *$ & 1.00 & 0.29 \\
\hline \multirow[t]{2}{*}{ Hepatic triglyceride (\%) } & Isoenergetic & 0.30 & 2.20 & -0.05 & 2.13 & 0.65 \\
\hline & Overfeeding & $1.70 *$ & 2.60 & $2.05^{*}$ & 2.89 & 0.73 \\
\hline \multirow[t]{2}{*}{$\operatorname{ALT}(\mathrm{U} / \mathrm{L})$} & Isoenergetic & -4.0 & 7.9 & -2.9 & 6.5 & 0.67 \\
\hline & Overfeeding & $* 5.8$ & 8.7 & 4.1 & 9.8 & 0.62 \\
\hline \multirow[t]{2}{*}{ Plasmatriglyceride $(\mathrm{mmol} / \mathrm{L})$} & Isoenergetic & -0.07 & 0.35 & 0.13 & 0.74 & 0.35 \\
\hline & Overfeeding & 0.36 & 0.75 & $0.33 * *$ & 0.39 & 0.91 \\
\hline \multirow[t]{2}{*}{$\mathrm{M}(\mathrm{mg} / \mathrm{kg} / \mathrm{min})$} & Isoenergetic & -0.29 & 1.46 & -0.68 & 0.83 & 0.58 \\
\hline & Overfeeding & -0.29 & 0.91 & -0.73 & 1.52 & 0.55 \\
\hline
\end{tabular}

Absolute change in parameters during intervention. $(*=P<0.05, * *=P<0.01$ compared to baseline value in that group)

There were no differences between a high fructose and glucose diet in relation to hepatic triglyceride or marker enzymes. The changes during the overfeeding period were strongly associated with changes in weight, reinforcing the interpretation that these were an energy, as opposed to a nutrient, specific effect. Clinical trials registry identifier: NCT01050140.

1. Bizeau ME \& Pagliassotti MJ (2005) Metabolism 54, 1189-201.

2. Stanhope KL, Schwarz JM, Keim NL et al. (2009) J Clin Invest 119, 1322-34.

3. Ngo Sock ET, Le KA, Ith M et al. (2010) Br J Nutr 103, 939-43. 